\title{
The potential for voluntary instruments to achieve conservation planning goals: the case of conservancies in South Africa
}

\author{
Linda Downs borough, Charlie M. Shackleton and ANDrew T. KNight
}

\begin{abstract}
Spatial prioritizations and gap analyses are increasingly undertaken to allocate conservation resources. Most spatial prioritizations are conducted without specifying the conservation instruments to be implemented and gap analyses typically assess formally protected areas but increasingly include private land conservation instruments. We examine conservancies to see if these voluntary instruments contribute towards achieving goals of South African conservation planning initiatives. We conducted a nationwide survey and interviews with conservancy members in Gauteng and the Eastern Cape. Conservancies have potential for assisting South Africa to achieve conservation planning goals at national and local scales but their inclusion in spatial prioritizations and gap analyses predicates improved protection for nature, operational refinement and increased support. We sound a warning to conservation planning initiatives that incorporate voluntary instruments on private land, and present recommendations for strengthening such instruments to make them more effective. Our findings may assist conservation planners elsewhere to design more effective conservation planning initiatives focused on private land.
\end{abstract}

Keywords Conservancy, community conservation, Eastern Cape, effectiveness, Gauteng, off-reserve conservation, optimal instrument mix

\section{Introduction}

The rate and extent of decline of nature through habitat I transformation, overharvesting and invasive alien species is of global concern. Protected areas represent the cornerstone of nature conservation efforts, aiming to ensure the persistence of species, habitats and environmental processes (Margules \& Pressey, 2000). The IUCN protected area categories span a spectrum from closed access to multiple uses (Anon., 2002). This classification recognizes that comprehensively achieving conservation goals will not

Linda Downsborough ${ }^{*}$, Charlie M. Shackleton (Corresponding author) and ANDREw T. KNIGHT ${ }^{\dagger}$ Department of Environmental Science, Rhodes University, Grahamstown, South Africa. E-mail c.shackleton@ ru.ac.za

${ }^{*}$ Current address: Monash University, Roodepoort, South Africa

${ }^{\dagger}$ Current address: Department of Conservation Ecology and Entomology, Stellenbosch University, Matieland, South Africa

Received 25 January 2010. Revision requested 28 June 2010.

Accepted 8 October 2010. be solely possible through formally protected areas but will require property rights-based instruments where conservation is mainstreamed into production activities on private land (Knight, 1999). Given the ad hoc history of protected area establishment targeting economically worthless lands (Pressey, 1994), a large proportion of high conservation value areas are now located on privately-owned lands outside protected areas (Ferrier et al., 2004), many of which face considerable pressure from destructive activities. Targeting conservation efforts on private land is therefore a priority for many conservation planning initiatives (Margules \& Pressey, 2000).

Conservation agencies increasingly apply computer-based techniques to identify efficient and representative networks of candidate protected areas (Pressey, 2002). Quantitative targets are applied to determine the extent to which existing protected areas achieve conservation targets (e.g. gap analyses) and/or to identify efficient, cost-effective additions to protected area networks (Margules \& Pressey, 2000). Although these approaches have focused primarily on formally protected areas, they are increasingly including a range of private land instruments (von Hase et al., 2003; Crossman \& Bryan, 2006; Wilson et al., 2007).

Compared to formally protected areas, private land instruments allow a balance between conservation and production (Anon., 2002), and are more cost effective (Pence et al., 2003) and socially acceptable (Western et al., 1994). They present opportunities for engaging and educating civil society, reduce opportunity costs of conservation, and are increasingly included in gap analyses and spatial prioritizations (Rouget et al., 2006). Private land instruments may be included in gap analyses as they can produce substantial increases in reported conservation effectiveness when conservation plans are evaluated using simplistic regional statistics such as total extent, or number of existing or proposed protected areas (Driver et al., 2005; Fishburn et al., 2009; Gallo et al., 2009). These quantitative criteria, however, are widely regarded as insufficient for evaluating the effectiveness of protected area networks (Pressey \& Taffs, 2001), as they make two flawed assumptions: (1) that the greater the extent of land under conservation management the more successful an initiative (Gallo et al., 2009), and (2) that management of these areas is sufficiently effective to ensure the persistence of nature.

Performance evaluations of networks of private land instruments have not been widely undertaken (Langholz \& 
Lassoie, 2001; Merenlender et al., 2004; Gallo et al., 2009). Recognizing that strategically locating private land instruments improves effectiveness (Forman \& Collinge, 1997), several studies have recently applied gap analyses (Ferrier et al., 2004). Gap analyses have been conducted on easements in the USA (Merenlender et al., 2004; Wallace et al., 2008; Fishburn et al., 2009) and on their financial cost-effectiveness (Pence et al., 2003; Wilson et al., 2007; Fishburn et al., 2009).

However, whilst gap analyses provide useful information on the achievement of regional-scale conservation goals (e.g. species sampled, connectivity enhanced), they offer little insight into whether management employed by private land instruments ensures the persistence of nature. Given the debatable effectiveness of some protected areas (Naughton-Treves et al., 2005), and that multiple-use activities may promote habitat transformation and fragmentation (Rissman et al., 2007) and decline of species (Lindsey et al., 2009), their effectiveness should not be assumed. Conservation planning initiatives should determine with reasonable certainty the effectiveness of private land instruments before including them in gap analyses or spatial prioritizations.

Conservancies are a well-recognized and increasingly popular private land management instrument in South Africa (Scholes, 2002; Cousins et al., 2008), with over 600 proclaimed. A conservancy comprises a voluntary agreement between private land managers to work together to manage their natural resources in an environmentally-friendly manner (NACSA, 2003). There are five types, identified by primary land-use and geographical location, with rural and urban conservancies the most common. Although the name suggests a primary focus on nature conservation, 'a conservancy is not a game reserve or nature reserve' (Kruger, 2005). However, anecdotal evidence suggests some conservancies are primarily established for this purpose. No formal regulations govern the management of conservancies, which are left to the constituent members. There are no legally-binding agreements, although they are registered with provincial conservation authorities and, if one exists, the provincial conservancy association. Limited guidelines exist directing the establishment of conservancies, although members must develop a constitution, which includes a mission statement and a broad outline of proposed management activities.

South Africa has widely embraced gap analyses and spatial prioritization (Knight et al., 2006b), which are now enshrined in legislation (National Environmental Management: Biodiversity Act, 2004). In conservation plans conservancies have generally been regarded as 'non-statutory reserves', providing a degree of protection for conservationworthy land (Cowling et al., 2003). More recently, it has been noted that conservancies 'do not provide secure long-term protection' (Driver et al., 2005) and may even be problematic for conservation because land managers with game or stock farms (who commonly implement conservancies) may persecute predators, overstock with game or domestic species, introduce extra-limital species or genetically manipulate huntable species (Lindsey et al., 2009).

Despite these issues conservancies have been included in gap analyses in most of South Africa's conservation plans (Driver et al., 2005), primarily assuming they are effective (Gallo et al., 2009) or represent areas where minimal investment will advance conservation goals (Rouget et al., 2006). Lindsey et al. (2009) identified several theoretical benefits of conservancies in a game ranching context but without examining their operations. No formal assessment of their suitability has been conducted.

We present benchmark information from two provinces in South Africa on the operation and conservation activities of conservancies, with a view towards understanding their effectiveness. We discuss the opportunities they present for the implementation of regional-scale conservation plans and recommend ways for improving their effectiveness. We did not include spatial analyses towards achieving conservation targets by conservancies as such analyses should follow the assessment of their suitability for such a role (Knight et al., 2006a).

\section{Study area}

South Africa is one of the most biologically diverse countries, with three of the 34 global conservation hotspots (Mittermeier et al., 2004). Private land conservation occupies $13.1 \%$ (16 million ha) of South Africa's land surface, over twice that of formally protected areas (Scholes, 2002). We evaluated two contrasting provinces. Gauteng, the smallest South African province $\left(17,010 \mathrm{~km}^{2}\right)$, has a total population of $>8.8$ million people and c. 520 people $\mathrm{km}^{-2}$ (Statistics South Africa, 2001). It is economically prosperous, highly industrialized, contributes c. $33 \%$ of South Africa's national gross domestic product (GDP) and contains large urban areas and limited natural landscapes. The Eastern Cape is South Africa's second largest province $\left(169,580 \mathrm{~km}^{2}\right)$, dominated mainly by agriculture and diverse natural environments. It is the poorest province with c. 6.3 million people and 38 people $\mathrm{km}^{-2}$ and has a very low per capita income.

The Eastern Cape comprises seven terrestrial biomes of which the Grassland, Nama Karoo, Subtropical Thicket and Savannah are the most extensive. The Forest and Fynbos biomes contain the highest numbers of threatened plant species. Gauteng comprises only two biomes, $71 \%$ being Grassland (GDACELA, 2004). The 6,160 plant species of the Eastern Cape is nearly double that of Gauteng. The two provinces have comparable numbers, but fundamentally different suites, of mammal, bird, amphibian and reptile species. Formally protected areas comprise c. 5\% of Gauteng province but they only protect $16 \%$ of the province's species (GDACELA, 2004). Only 5.3\% of the Eastern Cape is conserved in formally protected areas (ECDEAET, 2004), 
although this is increasing. Conservancies cover $8.3 \%$ and $11.6 \%$ of the Eastern Cape and Gauteng, respectively.

\section{Methods}

Two survey types were conducted, during May-August 2005. A postal survey was used to elicit a broad understanding of conservancies, and face-to-face interviews were used to obtain more detailed information. The aim of the postal survey was to collect information such as types of conservancies, reasons for establishment, spatial distribution and conservation activities. It was sent out to all registered conservancies in Gauteng $(\mathrm{n}=44)$ and the Eastern Cape $(\mathrm{n}=36)$, and distributed at the Third National Annual Conservancy Conference. The Conference provided an opportunity to interact with conservancies from other provinces and obtain a perspective on what is happening elsewhere in the country. Semi-structured interviews were conducted with the chairpersons of 15 randomly selected conservancies in both Gauteng and the Eastern Cape to obtain greater depth on the conservation effectiveness of conservancies.

The interview was divided into broad themes reflecting indicators of conservation effectiveness: (1) spatial design, (2) ecology (e.g. priority species), and (3) conservation action. Spatial design indicators were based upon Pressey \& Taffs (2001), and included number, size, connectivity and context of conservancies. Ecological indicators followed Duelli \& Orbrist (2003) and included rare, threatened and invasive alien species. Indicators of conservation action included conservancy meetings, restoration and rehabilitation projects, alien species eradication and community education and fund-raising projects.

Survey data were collated per province and entire sample, and frequencies calculated as percentages of the sample. Differences between provinces were examined with Mann-Whitney tests. Monetary values are reported in ZAR (USD $1=$ ZAR 6.20 at the time of the study).

\section{Results}

From the 80 postal surveys that were sent out to all registered conservancies in Gauteng and the Eastern Cape, 16 and 19 replies were received, respectively. With 20 replies at the National Conservancy Conference this gave a total of 55 responses (Table 1).

Types of conservancies The majority of conservancies surveyed through the postal and conference survey are rural (Table 1). Livestock farming is the primary land use in the Eastern Cape, with some small-scale cropping. Land use is more diverse in Gauteng, primarily small-scale agriculture or residential. Only one Gauteng conservancy has livestock; the majority comprise game farms, natural veld and wetlands. Conservation of nature or natural resources was the primary reason for establishing most conservancies (61\%). However, $21 \%$ of Eastern Cape
TABLE 1 Characteristics of conservancies in the Eastern Cape and Gauteng provinces of South Africa, identified from a postal survey $(\mathrm{n}=55)$.

\begin{tabular}{|c|c|c|c|c|}
\hline & \multicolumn{4}{|c|}{$\%$ of respondents } \\
\hline & $\begin{array}{l}\text { Eastern } \\
\text { Cape }^{1}\end{array}$ & \multicolumn{3}{|c|}{ Gauteng $^{2}$ Others ${ }^{3}$ Mean } \\
\hline \multicolumn{5}{|l|}{ Type } \\
\hline Rural & 95 & 81 & 73 & 83.0 \\
\hline Urban & 5 & 19 & 27 & 17.0 \\
\hline \multicolumn{5}{|l|}{ Primary land-use } \\
\hline Agriculture & 0 & 31 & 27 & 19.3 \\
\hline Game farm & 11 & 13 & 27 & 17.0 \\
\hline Livestock & 68 & 6 & 7 & 27.0 \\
\hline Natural land & 11 & 13 & 20 & 14.6 \\
\hline Urban/residential & 11 & 25 & 7 & 14.3 \\
\hline Wetland & 0 & 13 & 0 & 4.3 \\
\hline Other & 0 & 0 & 13 & 4.3 \\
\hline \multicolumn{5}{|l|}{ Reasons for establishment } \\
\hline Biodiversity conservation & 53 & 69 & 60 & 60.6 \\
\hline Ecotourism & 11 & 6 & 13 & 10.0 \\
\hline Fauna protection & 11 & 13 & 7 & 10.3 \\
\hline $\begin{array}{l}\text { Oppose residential } \\
\text { development }\end{array}$ & 5 & 6 & 0 & 3.6 \\
\hline Recreation & 0 & 6 & 13 & 6.3 \\
\hline Security & 21 & 0 & 7 & 9.3 \\
\hline \multicolumn{5}{|l|}{ Activities } \\
\hline Alien plant eradication & 95 & 94 & 87 & 92.0 \\
\hline Collaborative planning & 42 & 50 & 53 & 48.3 \\
\hline Community projects & 37 & 50 & 20 & 35.6 \\
\hline Educational awareness & 63 & 81 & 67 & 70.3 \\
\hline Fund-raising for conservation & 37 & 56 & 47 & 46.6 \\
\hline Meetings & 100 & 94 & 100 & 98.0 \\
\hline Special biodiversity projects & 47 & 44 & 33 & 41.3 \\
\hline Visit other conservancies & 21 & 81 & 20 & 40.6 \\
\hline \multicolumn{5}{|c|}{$\begin{array}{l}{ }^{1} \mathrm{n}=19 \\
{ }^{2} \mathrm{n}=16 \\
{ }^{3} \text { Results from } 20 \text { respondents who completed the postal survey distributed at } \\
\text { the National Association of Conservancies of South Africa conference; includes } \\
\text { respondents from KwaZulu Natal }(\mathrm{n}=3) \text {, Limpopo (7), Mpumalanga (7), } \\
\text { North West (2) and the Northern Cape (1) }\end{array}$} \\
\hline
\end{tabular}

conservancies were established for the security of livestock and game. Conservancies were also established for recreation, ecotourism, hunting and to oppose development.

Spatial characteristics of conservancies Conservancy size varies significantly $(H=18.54, \mathrm{P}<0.001)$ and is larger in the Eastern Cape (146-85,000 ha) than in Gauteng (3032,000 ha). Most Gauteng conservancies (73\%) are 30-5,000 ha in size whereas only $13 \%$ in the Eastern Cape are $<5,000$ ha, with $62 \%$ being $5,000-40,000$ ha. The total extent of the 30 interviewed conservancies is 505,948 ha (Eastern Cape) and 74,343 ha (Gauteng). All conservancies in the Eastern Cape (36) represent $8.3 \%$ of the area of the province, whereas Gauteng conservancies (44) represent 11.6\%. Both these figures are approximately double the percentage of land currently under formal protection within each province. Conservancy membership ranges from 5 to 280 people 
across the entire sample and is significantly different between provinces $(H=11.16, \mathrm{P}<0.01)$. Mean membership in the Eastern Cape is considerably less than in Gauteng. Eastern Cape conservancies are generally larger than those in Gauteng but have fewer members.

Financial characteristics and arrangements Most (62\%) conservancies charged annual membership fees of ZAR 303,000 and $66 \%$ charged $<$ ZAR 500 per annum. The mean annual fee for Gauteng and the Eastern Cape was similar, despite the significant difference in membership numbers. More than half $(58 \%)$ of Eastern Cape conservancies, compared to Gauteng (20\%), charged no membership fee. Total income for all conservancies did not differ significantly between provinces $(P>0.05)$, despite a range of ZAR 0-64,800. Annual income totalled ZAR 237,795 for the sampled conservancies in the Eastern Cape and ZAR 3,895,573 for those in Gauteng. Per hectare expenditure differed significantly $(H=9.4, \mathrm{P}<0.01)$ between Eastern Cape and Gauteng conservancies. The proportion of money spent on activities (e.g. alien plant eradication) was often very small in comparison to the total income of the conservancy, and was $1-5 \%$ of the total in a number of cases. Security, fencing, boom gates and game guard salaries comprised a large proportion of the spending of some conservancies, leaving little money for conservation activities. Some conservancies receive external funding, sponsorships or donations, which are used for various activities.

Conservation activities Gauteng conservancies conducted significantly $(Z=-2.3 \mathrm{P}<0.02)$ more conservation activities than Eastern Cape conservancies (Table 2). Gauteng conservancies were more proactive in undertaking educational awareness (to members or the wider community), projects in neighbouring communities, visiting other conservancies, and raising funds for conservation activities. Most conservancies undertook rehabilitation projects (e.g. soil erosion prevention, wetland restoration) either on an individual member basis or as a conservancy. All conserv-

TABLE 2 Types and number of activities conducted by conservancies in the Eastern Cape and Gauteng provinces.

\begin{tabular}{llcr}
\hline & \multicolumn{3}{l}{ \% of conservancies } \\
\cline { 2 - 4 } & Eastern & & \\
Activity & Cape & Gauteng & Mean \\
\hline Alien plant eradication & 100 & 100 & 100 \\
Community projects & 27 & 60 & 43 \\
Educational awareness & 33 & 100 & 67 \\
Meetings & 93 & 87 & 90 \\
Raise funds for conservation & 13 & 60 & 37 \\
Rehabilitation projects & 73 & 73 & 73 \\
Special biodiversity projects & 20 & 7 & 13 \\
Visit other conservancies & 40 & 67 & 53 \\
Mean no. of activities & $4 \pm 1.5$ & $6 \pm 1.7$ & \\
per conservancy \pm SD & & & \\
\hline
\end{tabular}

ancies eradicated alien plants from individual properties or from jointly managed areas. Membership meetings, during which members collectively discussed conservation and land management issues and ideas, were well supported by most conservancies.

Conservancies as conservation instruments The majority of conservancies in the Eastern Cape and Gauteng claimed to have rare or threatened species on their properties (Table 3 ). However, many were not aware of the presence of regionally or locally endemic species or even knew what they were, with $<50 \%$ of those interviewed in each province reporting endemic species within their conservancy. Connectivity of conservancies was generally poor, many being isolated from one another or protected areas by fencing. Only $7 \%$ of the conservancies in the Eastern Cape claimed contiguous and connected land use, and $33 \%$ in Gauteng. Conservancies with $0-10 \%$ transformed land were more common in the Eastern Cape than in Gauteng. The majority of Gauteng conservancies $(67 \%)$ reported $>10 \%$ of their land transformed and $20 \%$ reported $>50 \%$ transformation. The main forms of transformation included residential areas, fallow ploughed fields, roads and dams. Transformation resulting from invasive alien plants was low, with $93 \%$ in both provinces reporting $<20 \%$ infestation. The main invasive species differed between provinces: Opuntia aurantiaca and Acacia mearnsii prominent in the Eastern Cape, and Eucalyptus globulus and Populus sp. in Gauteng.

\section{Discussion}

Formal protected areas alone are unlikely to achieve regional conservation goals and thus private land instruments are crucial components of conservation planning (Margules \& Pressey, 2000). This is particularly the case in South Africa, where government has prioritized development over environmental goals. The political imperative to grow the economy, provide employment and reduce poverty requires that conservation interests engage this agenda through mainstreaming into other sectors, notably production landscapes.

Conservancies have obvious appeal for contributing towards conservation planning goals as they cover a significant proportion of South Africa's terrestrial extent. This potentially circumvents the time and expense of establishing new formal or private protected areas. They are voluntary and largely selffunded and known to most South Africans, especially citizens managing production landscapes presenting conservation opportunities. They offer potential for achieving landscapescale conservation through collaborative management across multiple individual managers (Rouget et al., 2006).

Given the widespread application of spatial prioritization in South Africa, coupled with the current global focus on the cost-effectiveness of conservation planning 
TABLE 3 Biological and habitat indicators for conservation effectiveness of conservancies in the Eastern Cape and Gauteng provinces.

\begin{tabular}{|c|c|c|}
\hline \multirow[b]{2}{*}{ Effectiveness indicator } & \multicolumn{2}{|c|}{$\%$ of conservancies } \\
\hline & $\begin{array}{l}\text { Eastern } \\
\text { Cape }\end{array}$ & Gauteng \\
\hline \multicolumn{3}{|l|}{ Conservation values } \\
\hline Rare or threatened species & 87 & 80 \\
\hline Endemic species & 40 & 27 \\
\hline Wetlands & 13 & 60 \\
\hline \multicolumn{3}{|l|}{ Landscape structure } \\
\hline Patchy & 93 & 67 \\
\hline Connected & 7 & 33 \\
\hline Corridors & 53 & 60 \\
\hline \multicolumn{3}{|l|}{ Extent transformed (\%) } \\
\hline $0-10$ & 53 & 33 \\
\hline $10-20$ & 27 & 0 \\
\hline $20-30$ & 13 & 13 \\
\hline $30-40$ & 0 & 13 \\
\hline $40-50$ & 0 & 20 \\
\hline$>50$ & 7 & 20 \\
\hline \multicolumn{3}{|l|}{ Alien infestation (\%) } \\
\hline $0-10$ & 53 & 40 \\
\hline $10-20$ & 40 & 53 \\
\hline $20-30$ & 0 & 7 \\
\hline $30-40$ & 7 & 0 \\
\hline \multicolumn{3}{|l|}{ Fencing } \\
\hline Individual properties & 93 & 93 \\
\hline Entire conservancy & 67 & 33 \\
\hline Land zonation plan & 27 & 13 \\
\hline
\end{tabular}

initiatives (Naidoo et al., 2006), conservancies can expect renewed attention, as they are cheaper to establish and manage than formally protected areas (Pence et al., 2003; Kruger, 2005). Funds raised by conservancies are generally diverted to conservation, either within the conservancy or the broader environment. However, the average annual funds spent by conservancies across our sample was ZAR $17.90 \mathrm{ha}^{-1}$ compared to that of c. ZAR $155.40 \mathrm{ha}^{-1}$ spent by South African National Parks (based on an annual budget of ZAR 558.6 million; South African National Parks, 2006). This limited expenditure is of concern if conservancies are to make a significant contribution to nature conservation given their voluntary status and, for example, the substantial costs of alien plant eradication.

Conservancy land managers individually bear land management costs delivering societal benefits, notably through their legal responsibility under the Conservation of Agricultural Resources Act (1983) for eradicating invasive alien plant species, which secures conservation targets and improves water provision for society (Görgens \& van Wilgen, 2004). On average, $92 \%$ of conservancy members undertake alien plant eradication from their individual, or neighbouring, properties, mostly at their own expense. This is a significant contribution towards achieving conservation goals and a substantial cost-saving to the State.
Conservancies undertake other voluntary activities of benefit to society, such as community conservation and raising environmental awareness. All Gauteng conservancies conduct educational awareness programmes, which vary greatly, from newsletters and brochures to youth education camps, tree-planting activities and school environmental clean-up days. These activities are important outreach activities that enhance social capital critical to the broader effectiveness of conservancies.

Conservancies have been classified as protected areas in both South African government planning (Driver et al., 2005; DEAT, 2006) and internationally-funded regional conservation plans (Cowling et al., 2003; Rouget et al., 2006). However, they have not been included in national gap analyses because of the uncertain protection they provide nature (Driver et al., 2005). Caution regarding their inclusion in spatial prioritizations is warranted. Conservancies are popular with both rural and urban land managers, who often assume they are able to maintain economically viable production activities whilst simultaneously achieving conservation (Kruger, 2005). However, the notion that voluntary private land instruments guarantee conservation is tenuous (Pressey \& Taffs, 2001; Rissman et al., 2007). Successfully fusing conservation and development is difficult in practice (Naughton-Treves et al., 2005).

The utility of conservancies for achieving conservation planning goals depends upon their potential to secure nature in perpetuity in the context of multiple use. Spatial design indicators are indirect measures of conservation effectiveness and conservancy members' perceptions of their effectiveness may be value-laden. With greater time and resources the ecological dimensions that indicate human-induced transformation could have been surveyed. Anecdotal evidence suggests that in many locations stocking rates, whilst not high, should be reduced and specific areas fenced for habitat and species of special concern to be conserved. Given their statutory and land tenure context, the security afforded by conservancies hinges upon the values of individual land managers.

Their voluntary nature and lack of scientificallydefensible guidelines means conservancies fail to meet the expectations of many conservation professionals. However, if effectively strengthened, conservancies potentially offer an important instrument for achieving conservation planning goals. We outline recommendations for improving the effectiveness of voluntary private land instruments towards achieving conservation planning goals, based on the findings of this study, our experience and the literature.

\section{Recommendations}

Provide support and information through regional or national associations Networks of private land instruments such as conservancies need to be supported by regional or 
national associations that (1) cultivate a common vision, (2) motivate members, (3) provide advice and advocacy, (4) facilitate communication, (5) coordinate cooperative development of standards and guidelines between land managers, government and conservation professionals, and (6) foster social learning. Facilitative associations are superior to prescriptive ones, especially regarding voluntary agreements, as the diversity and flexibility of voluntary agreements can be pivotal to their success. Conservation professionals should not unwittingly undermine the enthusiasm and motivation that inspired private land instruments through efforts to restructure their administration and financing (Paton et al., 2004). Training in a range of skills that support both natural resource management and business goals is critical for activities such as threatened species management, alien plant eradication and soil conservation techniques.

Assist development of management plans Conservancies, like other voluntary instruments, submit a management plan to the provincial association when they register but it is not binding and there are no minimum standards for achieving conservation goals. Land managers may perceive their land-use activities to be more compatible with conservation goals than practically possible. A management plan is, therefore, essential for effectively integrating conservation and production activities, providing clear goals and tangible measures of success, and identifying essential future research (Margoluis \& Salafsky, 1998). Private land instruments contribute most to achieving conservation planning goals when multiple agreements are located contiguously and managed collectively using common pool approaches. This promotes flows of capital (e.g. natural, social, financial) through enhanced connectivity (Rouget et al., 2006) and reduces management costs (Brunckhorst \& Coop, 2003; Pence et al., 2003). However, these approaches are complex to implement and require substantial investments of time and resources to be effective (Brunckhorst \& Coop, 2003). A management plan should be collaboratively developed by all members of multi-land manager agreements, with assistance from the regional association and relevant government agencies, to ensure it is set in the policy context of natural resource management and other social issues such as land reform. Land managers should be assisted with useful information, including relevant legislation, government initiatives and funding sources, advances in technology, local natural features, and ecosystem services of regional, national or global significance, and climate change.

Implement targeted incentives Incentives (e.g. tax rebates, support for land rehabilitation and alien plant eradication) can be critical for securing and maintaining land manager involvement. Incentives should be linked to a tiered suite of agreements of increasing benefit to land managers. For example, conservancies could provide the first step in a ladder of tenure-based instruments of increasing conservation security. Voluntary agreements should be complemented with basic incentives, such as receiving conservation support and advice, to encourage private land managers to manage land to achieve conservation planning goals. Offering more substantial incentives to land managers who sign-up to binding agreements (e.g. targeted government-funded eradication of invasive alien plants) could encourage land managers to commit in perpetuity. Incentives don't have to be monetary (Doremus, 2003): they can be, for example, awards that recognize conservation contributions.

Provide targeted financial support Boosting conservationfocused activities with funds and resourcing is an obvious way to improve effectiveness but large-scale government investment and control should be carefully situated and managed. This type of investment can initially increase conservation gains but has the potential to erode existing social capital and institutional strength (Paton et al., 2004), and ultimately prove counter-productive if insufficiently funded (Doremus, 2003). Resources should be focused not only in areas of high natural capital but also of lower conservation value but high human and social capital (Cowling et al., 2010). These arrangements should be conceived in the broader context of developing an optimal mix of instruments and institutions that complement both private and formally protected areas.

Encourage social learning and adaptive management The conservation context of most regions will change significantly over time through fluctuating commodity prices, land degradation, species migration, climate change and the establishment of new protected areas (Smith et al., 2009). Consequently, establishing social learning institutions is a primary goal of effective conservation planning initiatives (Knight et al., 2006a). Social learning is the process of iterative reflection that aims to improve useful knowledge to support collective action and occurs through partnerships where experiences, ideas and environments are shared (Keen et al., 2005). A social learning institution that regularly brings researchers, practitioners and land managers together to discuss and implement on-going refinements to land management practices is highly beneficial for land managers, but requires strong commitment from participants to be effective.

\section{Conclusion}

Conservation planning is increasingly applied to solve regional conservation problems (Knight et al., 2006b). Private land instruments potentially offer greater benefits than formal protected areas for achieving conservation planning goals, as land managers willing to sell their land may often be far fewer in number than those willing to engage private land agreements, and potentially incur fewer 
opportunity costs. However, many conservation plans assume that voluntary private land instruments provide sufficient security to ensure the persistence of nature without ever having evaluated the instruments' effectiveness, either in terms of ensuring persistence of valued natural features or the willingness and capacity of stakeholders to implement these instruments. Conservancies in South Africa provide one such example. Whilst conservancies have the potential to be a significant conservation instrument for achieving domestic conservation goals (Driver et al., 2005) and contribute to a country's international commitments, they also require greater support at the local scale and improved facilitation at provincial and national scales. The development of a landscape management model that includes conservancies, such as the Megaconservancy Network concept (Rouget et al., 2006), will only be successfully implemented once conservancies are sufficiently supported and complemented with other conservation instruments that promote the financial security of land managers whilst providing them with the opportunity collectively to achieve conservation goals. This case study of South African conservancies provides an example of the importance of, firstly, evaluating instruments to be applied through spatial prioritizations and, secondly, ensuring transparent collaborative processes between conservation planners and other stakeholders to formulate land management models that comprise an optimal mix of conservation instruments cognizant of the implementation opportunities and constraints that define conservation opportunity.

\section{Acknowledgements}

The conservancy members that participated in this study are sincerely thanked for their contributions. Rhodes University provided support for this work, as did the Nelson Mandela Metropolitan University and Stellenbosch University (to ATK).

\section{References}

ANON. (2002) The IUCN Protected Area Management Categories. Information sheet number 3. Http://www.unep-wcmc.org/ protected_areas/categories/index.html [accessed 14 March 2008].

Brunckhorst, D.J. \& Coop, P. (2003) Tilbuster commons: synergies of theory and action in new agricultural commons on private land. Ecological Management and Restoration, 4, 13-22.

Cousins, J.A., S ADLER, J.P. \& Evans, J. (2008) Exploring the role of private wildlife ranching as a conservation tool in South Africa: stakeholder perspectives. Ecology and Society, 13, 43.

Cowling, R.M., Knight, A.T., Privett, S.D.J. \& Sharma, G. (2010) Invest in opportunity, not inventory of hotspots. Conservation Biology, 24, 633-635.

Cowling, R.M., Pressey, R.L., Rouget, M. \& Lombard, A.T. (2003) A conservation plan for a global biodiversity hotspot-the Cape Floristic Region, South Africa. Biological Conservation, 112, 191-216.
Crossman, N.D. \& Bryan, B.A. (2006) Systematic landscape restoration using integer programming. Biological Conservation, $128,369-383$.

DeAT (Department of Environmental Affairs and Tourism) (2006) South Africa Environment Outlook. A Report on the State of the Environment. Department of Environmental Affairs and Tourism, Pretoria, South Africa.

Doremus, H. (2003) A policy portfolio approach to biodiversity protection on private lands. Environmental Science and Policy, 6, 217-232.

Driver, A., Maze, K., Rouget, M., Lombard, A.T., Nel, J., Turpie, J.K. et al. (2005) National Spatial Biodiversity Assessment 2004: Priorities for Biodiversity Conservation in South Africa. Strelitzia 17. South African National Biodiversity Institute, Pretoria, South Africa.

Duelli, P. \& Orbrist, M.K. (2003) Biodiversity indicators: the choice of values and measures. Agriculture, Ecosystems and Environment, 98, 87-98.

eCDEAet (Eastern Cape Department of Economic Affairs, EnviRONMENT AND Tourism) (2004) Eastern Cape State of the Environment Report 2004. ECDEAET Bisho, South Africa.

Ferrier, S., Powell, G.V.N., Richardson, K.S., Manion, G., Overton, J.M., Allnutt, T.F. et al. (2004) Mapping more of terrestrial biodiversity for global conservation assessment. BioScience, 54, 1101-1109.

Fishburn, I.S., Kareiva, P., Gaston, K.J. \& Armsworth, P.R. (2009) The growth of easements as a conservation tool. PLoS One, 4(3), e4996.

Forman, R.T.T. \& Collinge, S.K. (1997) Nature conserved in changing landscapes with and without spatial planning. Landscape and Urban Planning, 37, 129-135.

Gallo, J.A., Pasquini, L., Reyers, B. \& Cowling, R.M. (2009) The role of private conservation areas in biodiversity representation and target achievement within the Little Karoo region, South Africa. Biological Conservation, 142, 446-454.

gDacela (Gauteng Department of Agriculture, Conservation, Environment and Land Affairs) (2004) Gauteng State of the Environment Report 2004/2005. Http://www.environment.gov.za/ soer/ [accessed 14 March 2008].

Görgens, A.H.M. \& van Wilgen, B.W. (2004) Invasive alien plants and water resources in South Africa: current understanding, predictive ability and research challenges. South African Journal of Science, 100, 27-33.

Keen, M., Brown, V.A. \& Dyball, R. (2005) Social Learning in Environmental Management: Towards a Sustainable Future. Earthscan, London, UK.

KNight, R.L. (1999) Private lands: the neglected geography. Conservation Biology, 13, 223-224.

Knight, A.T., Cowling, R.M. \& Campbell, B.M. (2006a) An operational model for implementing conservation action. Conservation Biology, 20, 408-419.

Knight, A.T., Driver, A., Cowling, R.M., Maze, K., Desmet, P.G., Lombard, A.T. et al. (2006b) Designing systematic conservation assessments that promote effective implementation: best practice from South Africa. Conservation Biology, 20, 739-750.

Kruger, A.T. (2005) Conservancy, Biodiversity and Farming: A Long Story. Unpublished Report to Gauteng Conservancy Association, Johannesburg, South Africa.

Langholz, J.A. \& Lassoie, J.P. (2001) Perils and promise of privately owned protected areas. BioScience, 51, 1079-1085.

Lindey, P.A., Romañach, S.S. \& Davies-Mostert, H.T. (2009) The importance of conservancies for enhancing the value of game ranch land for large mammal conservation in southern Africa. Journal of Zoology, 277, 99-105. 
Margoluis, R. \& Salafsky, N. (1998) Measures of Success: Designing, Managing and Monitoring Conservation and Development Projects. Island Press, Washington, DC, USA.

Margules, C.R. \& Pressey, R.L. (2000) Systematic conservation planning. Nature, 405, 243-253.

Merenlender, A.M., Huntsinger, L., Guthey, G. \& Fairfax, S.K. (2004) Land trusts and conservation easements: who is conserving what for whom? Conservation Biology, 18, $65-75$.

Mittermeier, R.A., Hoffmann, M., Pilgrim, J.D., Brooks, T.M., Mittermeier, C.G., Lamoreux, J.F. et al. (2004) Hotspots Revisited: Earth's Biologically Richest and Most Endangered Ecoregions. Cemex, Mexico City, Mexico.

NACSA (National Association of Conservancies of South Africa) (2003) Conservancies Handbook. NACSA, Johannesburg, South Africa.

Naidoo, R., Balmford, A., Ferraro, P.J., Polasky, S., Ricketts, T.H. \& Rouget, M. (2006) Integrating economic costs into conservation planning. Trends in Ecology \& Evolution, $21,681-687$.

Naughton-Treves, L., Holland, M.B. \& Brandon, K. (2005) The role of protected areas in conserving biodiversity and sustaining local livelihoods. Annual Review of Environment and Resources, 30, 219-252.

Paton, S., Curtis, A., McDonald, G. \& Woods, M. (2004) Regional natural resource management: is it sustainable? Australasian Journal of Environmental Management, 11, 260-267.

Pence, G.Q.K., Botha, M.A. \& Turpie, J.K. (2003) Evaluating combinations of on- and off-reserve conservation strategies for the Agulhas Plain, South Africa: a financial perspective. Biological Conservation, 112, 253-273.

Pressey, R.L. (1994) Ad hoc reservations: forward or backward steps in developing representative reserve systems? Conservation Biology, 8, 662-668.

PRESSEY, R.L. (2002) The first reserve selection algorithm-a retrospective on Jamie Kirkpatrick's 1983 paper. Progress in Physical Geography, 26, 434-442.

Pressey, R.L. \& TAFFs, K.H. (2001) Scheduling conservation action in production landscapes: priority areas in western New South Wales defined by irreplaceability and vulnerability to vegetation loss. Biological Conservation, 100, 355-376.
Rissman, A.R., Lozier, L., Comendant, T., Kareiva, P., Kiesecker, J.M., Shaw, M.R. et al. (2007) Conservation easements: biodiversity protection and private use. Conservation Biology, 21, 709-718.

Rouget, M., Cowling, R.M., Lombard, A.T., Knight, A.T. \& Kerley, G.I.H. (2006) Designing large-scale conservation corridors for pattern and process. Conservation Biology, 20, 549-561.

Scholes, B. (2002) Biodiversity Conservation Outside of Formally Protected Areas. Unpublished Report to CSIR Environmentek, Pretoria, South Africa.

Smith, R.J., Verissimo, D., Leader-Williams, N., Cowling, R.M. \& Knight, A.T. (2009) Let the locals lead. Nature, 462, $280-281$

Statistics South Africa (2001) South African National Census Data. Http://www.statssa.gov.za [accessed 14 March 2008].

von Hase, A., Rouget, M., Maze, K. \& Helme, N. (2003) A Fine-scale Conservation Plan for Cape Lowlands Renosterveld: Technical Report. Report No. CCU 2/03. Cape Conservation Unit, Botanical Society of South Africa, Cape Town, South Africa.

Wallace, G.N., Theobald, D.M., Ernst, T. \& King, K. (2008) Assessing the ecological and social benefits of private land conservation in Colorado. Conservation Biology, 22, 284-296.

Western, D., Wright, R.M. \& Strum, S. (eds.) (1994) Natural Connections: Perspectives in Community-based Conservation. Island Press, Washington, DC, USA.

Wilson, K.A., Underwood, E.C., Morrison, S.A., Klausmeyer, K.R., Murdoch, W.W., Reyers, B. et al. (2007) Maximising the conservation of the world's biodiversity: what to do, where and when. PLoS Biology, 5(9), e223.

\section{Biographical sketches}

The authors have a diverse range of interests focused upon the sustainable use of natural resources, including environmental education, sustainable use of plant species by subsistence users, the role of protected areas in achieving sustainable development, and social learning institutions promoting adaptive management. They believe that understanding and working towards bridging the gap between research and management is fundamental to ensuring the collective action required for achieving sustainable development. 